\title{
Quality assurance for family practice trainees in the USA and the UK: too little too late?
}

\author{
R. BAKER \& L. GREEN† \\ General Practice Unit, Department of Epidemiology and Community Medicine, University of Bristol and \\ †Department of Family Medicine, University of Michigan, Ann Arbor
}

\begin{abstract}
Summary. A postal survey about opinions of quality assurance and the methods used to teach this subject was sent to all family practice course organizers in England, Wales and Scotland, and to all family practice residency directors in the USA. Opinions of quality assurance were more positive from the American responders. A wide variety of teaching methods was employed, with review of records for the quality of care more common in the USA, but trainees in the UK were more likely to participate in quality assurance, rather than merely being exposed to it. However, the proportion of trainees in either country that undertook projects was disappointingly low. The teaching of quality assurance to trainees needs to be given a higher priority in both the USA and UK.
\end{abstract}

Key words: *qual assur; *attitude of health personnel; *internship; family practice/educ; United States; Great Britain

\section{Introduction}

The role of quality assurance in health care is now of growing interest to many countries, stimulated by the universal problem of increasing costs and concern about the quality of care. Family doctors working as generalists who occasionally call on the services of specialists have been described as the 'gatekeepers' into the system of health care (Rosenblatt \& Moscovice 1984; Day $\&$ Klein 1986) both in the USA and the UK. In this role they have a considerable influence on how much is spent on the care of individual

Correspondence: Dr R. H. Baker, 17 Moorend Park Road, Leckhampton, Cheitenham, Gloucestershire GL53 OLA, UK. patients, and so the specialty may to a large extent determine the total health-care budget. In addition to expenditure, quality is now subject to greater scrutiny. In the UK there has been criticism of the quality of care in family practice (Irvine 1983), whilst in the mixed health economy of the USA there is a continuing debate about which type of provider offers the best quality in primary care (Yankauer 1980). If family doctors are to undertake quality assurance themselves, or participate in the quality assurance systems of health-care agencies, they need the appropriate knowledge, skills and attitudes. There is then an important role for the trainers of family doctors in the teaching of quality assurance.

The term 'family doctor' is used in this paper to refer to the British general practitioner and to doctors in the USA who have undergone specific training in family practice residency programmes. Likewise, the term 'family practice' is used to include British general practice and the work of family doctors in the USA. The American residency programmes are comparable with the vocational training schemes in the UK. The final place of work in the USA for these family doctors may range from small-town independent practice to employment as cost-effective 'gatekeepers' in inner-city health-maintenance organizations. There are now many residency programmes for family doctors, and the importance of the specialty is becoming more accepted.

Because the two countries have different health-care systems, quality assurance is used in different ways. In the USA health care is an industry that sells its wares to patients, insurance companies and to government. The providers of care have to remain solvent, and many have to 
make a profit. The conflict between those who have to pay for the industry and those who wish to make money from it has been raging for many years, and a number of strategies have been tried to control both cost and quality. Quality assurance has been one of these, and it has been promoted by those who pay for care (government, insurance companjes) as well as those who sell care and need to maintain reasonable profit margins. It is the doctors who spend the money, and their work has increasingly been subject to quality assurance by managers through institutionalized quality assurance programmes designed for cost containment. Moreoever, accreditation by one of several bodies is needed to sell care to government or insurance companies, and one of the usual criteria for accreditation is organized quality assurance.

In contrast, the system of care in the UK is a public service funded from taxation, with cost controlled at source. Because of this more direct way of controlling expenditure, the stimulus for quality assurance has been less intense. It has been individual family doctors using quality assurance in their own practices who have shown the potential benefits that might accrue. In recent years, many will have conducted simple 'audits' (as quality assurance is sometimes called in the UK) on their own clinical care. Concern over the cost of care has often taken second place. However, with the publication of the government's proposals for reform of the National Health Service (Secretaries of State for Health, Wales, Northern Ireland and Scotland 1989) this may all change with the introduction of audit committees in Family Practitioner Committees and the emphasis on cost-effectiveness.

This study sought to test the following hypotheses. Firstly, because quality assurance in the USA is used by managers to contain costs, the opinions of family practice residency directors will be less positive towards quality assurance than their UK counterparts. Secondly, because the subject has a longer history in the USA, teaching will be more advanced in that country, but thirdly, because of the tradition of in-practice 'audits', trainees in the UK will be more likely to undertake projects.

\section{Methods}

A 23-item questionnaire (copies of which are available on request from the authors) was designed to include measures of teachers' opinions of quality assurance and the teaching of this subject to trainees using a 5-point scale. One section asked respondents to rank in order of value four types of quality assurance activity (personal studies, peer review, external review and outcome review), and another section asked about methods that can be used to teach quality assurance. The respondents were also asked to estimate the proportion of trainees on the course who undertook quality assurance projects.

Careful attention to the language of the questionnaire was necessary, as English is used differently on each side of the Atlantic. Eventually, what can best be described as mid-Atlantic English was adopted, so that the questionnaire would be equally easy or difficult to complete for British and American doctors. The terms used were qualified by examples as shown in the accompanying tables. The terminology of this subject is extensive and confusing, so respondents were told that for the purposes of this study quality assurance was assumed to include medical audit, performance review, peer review and utilization review.

The questionnaire was sent in June 1987 to all family practice course organizers in England, Wales and Scotland, and to all family practice residency directors in the USA. Training is managed in different ways in the two countries, in the USA there being a single residency director, whilst in the UK there are usually several course organizers. There was no satisfactory method of selecting one answer from each UK course, so all have been used. The statistical tests used were $\chi^{2}$ and Mann Whitney's $U$ test.

\section{Results}

There were 334 course organizers in England, Wales and Scotland listed by the Association of Course Organizers, and $248(74-25 \%)$ returned usable questionnaires. In the USA there were a total of 381 residency directors listed by the American Academy of Family Practice, and 257 $(67.45 \%)$ replied. The difference in response rate was not statistically significant. The difficulties of studying in two countries precluded a second mailing. There is no information on non-responders. The respondents managed the questionnaire despite the mid-Atlantic language, as 
Table 1. Attitudes of course organizers/residency directors to quality assurance (QA) in general practice and as a subject for teaching. Numbers in brackets are percentages

\begin{tabular}{|c|c|c|c|c|c|}
\hline \multicolumn{3}{|c|}{$\begin{array}{l}\text { In ensuring high standards } \\
\text { of care in family } \\
\text { practice, quality } \\
\text { assurance is: }\end{array}$} & \multicolumn{3}{|c|}{$\begin{array}{l}\text { In the training of family } \\
\text { practice trainees, the } \\
\text { subject of quality } \\
\text { assurance is: }\end{array}$} \\
\hline & UK & USA & & UK & USA \\
\hline Essential & $96(38 \cdot 7)$ & $135(52 \cdot 7)$ & Essential & $101(40 \cdot 7)$ & $131(50 \cdot 9)$ \\
\hline Very useful & $90(36 \cdot 3)$ & $71(27 \cdot 7)$ & $\begin{array}{l}\text { Very } \\
\text { important }\end{array}$ & $96(38 \cdot 7)$ & $76(29 \cdot 6)$ \\
\hline Useful & $56(22 \cdot 6)$ & $38(15 \cdot 4)$ & Important & $46(18.5)$ & $42(16 \cdot 3)$ \\
\hline $\begin{array}{l}\text { Marginally } \\
\text { useful }\end{array}$ & $6 \quad(2 \cdot 4)$ & $11(4 \cdot 3)$ & $\begin{array}{l}\text { Marginally } \\
\text { important }\end{array}$ & $5 \quad(2 \cdot 0)$ & $8 \quad(3 \cdot 1)$ \\
\hline $\begin{array}{l}\text { Wasted } \\
\text { effort }\end{array}$ & 0 & $1 \quad(0 \cdot 4)$ & Irrelevant & 0 & 0 \\
\hline$P<0.01$ & & & NS & & \\
\hline
\end{tabular}

evidenced by the relatively small number of missed items and comments on the form.

The comparison of opinions towards quality assurance held by the organizers of training for family doctors did not support the first hypothesis. The respondents from the USA were more likely to feel that quality assurance was essential for ensuring high standards of care in family practice, although there was no difference in the attitudes held about the importance of the subject for training (Table 1).

Respondents were asked to rank in order four different types of quality assurance activity according to their views of the value of each in family practice (Table 2 ). The UK respondents favoured personal studies and peer review, whilst the USA respondents also chose peer review but placed more importance than the UK replies on outcome reviews such as morbidity or mortality conferences and less importance on personal studies. External review used for accreditation or the good practice allowance (Secretaries of State for Social Services, Wales, Northern Ireland and Scotland 1986) was seen in both countries as of least value. Contrary to the first hypothesis, therefore, it would appear that the teachers of family practice from the UK in this survey equally reject this form of quality assurance although they have less experience of it than their counterparts in the USA.

Table 2. The number of course chiefs assigning different rank orders of value (one highest, four lowest) for four methods of QA (\%)

\begin{tabular}{|c|c|c|c|c|c|c|c|c|}
\hline \multirow[b]{2}{*}{ Rank } & \multicolumn{2}{|c|}{$\begin{array}{c}\text { Personal } \\
\text { studies }\end{array}$} & \multicolumn{2}{|c|}{$\begin{array}{c}\text { Peer } \\
\text { review }\end{array}$} & \multicolumn{2}{|c|}{$\begin{array}{c}\text { External } \\
\text { review } \\
\text { (e.g. accreditation, } \\
\text { good practice allowance) }\end{array}$} & \multicolumn{2}{|c|}{$\begin{array}{c}\text { Outcome } \\
\text { review } \\
\text { (e.g. morbidity or } \\
\text { mortality conferences) }\end{array}$} \\
\hline & UK & USA & UK & USA & UK & USA & UK & USA \\
\hline 1 & $97(46 \cdot 6)$ & $60(24.8)$ & $93(44 \cdot 7)$ & $132(54.5)$ & $12(5.8)$ & $11(4 \cdot 5)$ & $6(2 \cdot 9)$ & $39(16 \cdot 1)$ \\
\hline 2 & $74(35.6)$ & $43(17 \cdot 8)$ & $86(41 \cdot 3)$ & $72(29.8)$ & $18(8 \cdot 7)$ & $36(14 \cdot 9)$ & $31(15 \cdot 0)$ & $91(37 \cdot 6)$ \\
\hline 3 & $21(10 \cdot 1)$ & $76(31.4)$ & $23(11 \cdot 1)$ & $23(9.5)$ & $61(29 \cdot 3)$ & $64(26.4)$ & $101(48-8)$ & $79(32.6)$ \\
\hline 4 & $16(7 \cdot 7)$ & $63(26.0)$ & $6(2.9)$ & $15(6 \cdot 2)$ & $117(56 \cdot 3)$ & $131(54 \cdot 1)$ & $69(33.3)$ & $33(13 \cdot 6)$ \\
\hline & $P<0.001$ & & NS & & NS & & $P<0.001$ & \\
\hline
\end{tabular}


The different attitudes to quality assurance are reflected to some extent in the reported methods used to teach the subject to trainees. In the USA trainees are more likely to be exposed to outcome reviews in the form of morbidity or mortality conferences, whilst in the UK exposure to inpractice reviews on topics such as antibiotic use is reported as more likely (Table 3 and Fig. 1). Trainees in the UK are more likely to participate in quality assurance rather than merely be exposed to it taking place in the practice. Because of this, they are more likely to participate in setting standards, reviewing specific problems and reviewing records. However, all these activities are components of project work, and may simply reflect the greater use of this method in the UK. In the UK, more course organizers reported the trainees undertook projects of their own, but comparison of UK and USA courses where projects were reported did not show a different proportion of trainees undertaking projects, the median in UK courses being $30 \%$, and the median in the USA 20\% (Mann Whitney test not significant).

The respondents report that trainees in the UK are more likely to receive formal descriptions of

Table 3. The types of training which are regular parts of training schemes in the UK and USA. Numbers in brackets are percentages. (Results displayed in the Fig.1)

\begin{tabular}{|c|c|c|c|c|c|}
\hline & & & UK & USA & $P$ \\
\hline (1) & \multicolumn{2}{|c|}{ Formal description } & $189(76 \cdot 5)$ & $178(69 \cdot 3)$ & $<0.01$ \\
\hline \multirow[t]{6}{*}{$(2)$} & \multicolumn{2}{|c|}{$\begin{array}{l}\text { In-practice QA to which trainees } \\
\text { are exposed } \\
\text { Including: }\end{array}$} & $242(99 \cdot 2)$ & $254(98 \cdot 8)$ & NS \\
\hline & (a) & $\begin{array}{l}\text { external review } \\
\text { (e.g. accreditation, good } \\
\text { practice allowance) }\end{array}$ & $114(46-7)$ & $133(51 \cdot 8)$ & NS \\
\hline & (b) & $\begin{array}{l}\text { outcome reviews } \\
\text { (e.g. morbidity or } \\
\text { mortality conferences) }\end{array}$ & $112(45 \cdot 9)$ & $164(63 \cdot 8)$ & $<0.001$ \\
\hline & (c) & $\begin{array}{l}\text { specific reviews in-practice } \\
\text { (e.g. antibiotic use, } \\
\text { oxygen prescriptions) }\end{array}$ & $210(86 \cdot 1)$ & $134(52 \cdot 1)$ & $<0.001$ \\
\hline & (d) & $\begin{array}{l}\text { record review for quality } \\
\text { of records }\end{array}$ & $222(91-0)$ & $236(91 \cdot 8)$ & NS \\
\hline & (e) & $\begin{array}{l}\text { record review for quality } \\
\text { of care }\end{array}$ & $199(81 \cdot 6)$ & $234(91 \cdot 1)$ & $<0.01$ \\
\hline (3) & \multicolumn{2}{|c|}{$\begin{array}{l}\text { Trainee participates in QA } \\
\text { Including: }\end{array}$} & $240(98.4)$ & $232(90-3)$ & $<0.001$ \\
\hline & (a) & setting standards & $127(52 \cdot 0)$ & $101(39 \cdot 3)$ & $<0.01$ \\
\hline & (b) & specific problem reviews & $205(84-0)$ & $165(64 \cdot 2)$ & $<0.001$ \\
\hline & (c) & reviews own records & $194(80 \cdot 2)$ & $126(49 \cdot 0)$ & $<0.001$ \\
\hline & (d) & $\begin{array}{l}\text { reviews other doctors' } \\
\text { records }\end{array}$ & $141(58 \cdot 5)$ & $100(39 \cdot 9)$ & $<0.001$ \\
\hline & (e) & reviews own quality of care & $183(75 \cdot 9)$ & $127(49 \cdot 4)$ & $<0.001$ \\
\hline & (f) & $\begin{array}{l}\text { reviews other doctors' } \\
\text { quality of care }\end{array}$ & $129(53.5)$ & $104(40-5)$ & $<0.01$ \\
\hline (4) & \multicolumn{2}{|c|}{ Trainees undertake projects } & $204(85 \cdot 7)$ & $80(31 \cdot 1)$ & $<0.001$ \\
\hline
\end{tabular}




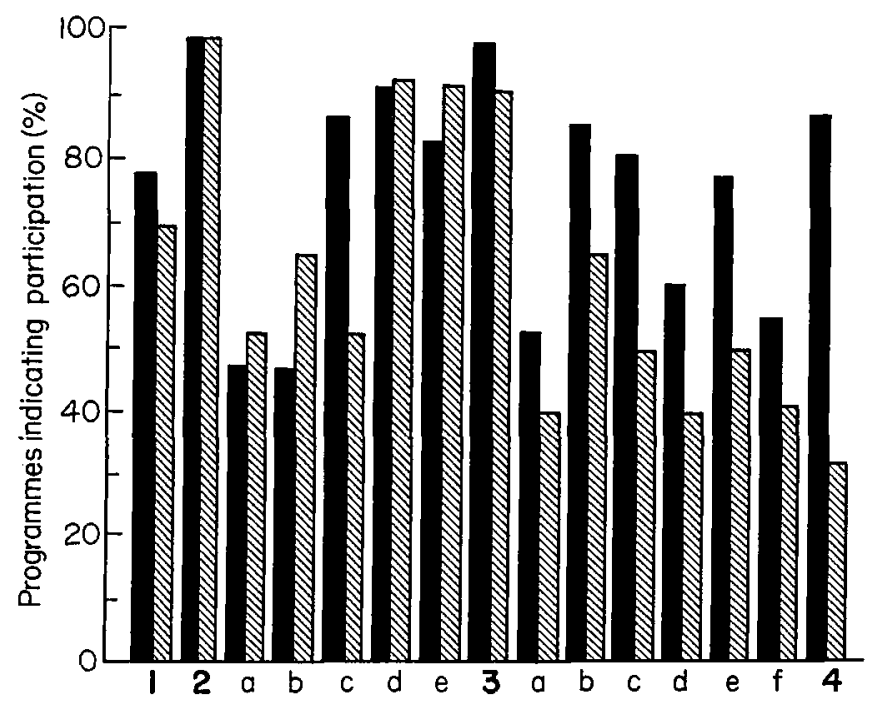

Figure 1. Quality assurance training activities (see Table 3 for key to categories; dark bars are UK responses, shaded are USA).

quality assurance by means of lectures or seminars (Table 3). Whether these descriptions are provided in the training practice or as part of the course outside the practice cannot be determined by this study. However, these findings do not support the second hypothesis that teaching would be more advanced in the USA, but the third hypothesis which suggested that projects would be more common in the UK was given some support.

\section{Discussion}

This study reports the views of course organizers and residency directors of the teaching in quality assurance that trainees receive. The perceptions of these course organizers are not necessarily accurate, and they are unlikely to be fully aware of every teaching encounter that trainees on their courses experience. The results of this study should be interpreted in this light, but there is no reason to believe that course organizers from one country were any more or less informed than those from the other. The difficulties presented by the terminology of quality assurance, which varies in detail between different countries, were addressed by providing specific examples for most of the terms used on the questionnaire. It is therefore unlikely that the differences shown in this study are merely differences in the interpretation of terminology. The most likely explanation for the findings is that there are differences in the opinions of quality assurance, the methods used to teach it, and its role in family practice.

In the UK, opinions of quality assurance held by the teachers of general practice could be more positive, with only $38.7 \%$ of course organizers rating the activity essential to ensuring high standards of care. In the USA, increased acceptance of quality assurance might be achieved by the encouragement of more resident projects. This should enable family doctors to monitor care themselves rather than rely on management. The proportion of courses in the UK reporting projects is greater, but the number of trainees participating in this activity is still relatively small. The potential of this means of education to foster an enquiring spirit and learn some of the methods of research and quality assurance has yet to be realized. It is disappointing to find, after the many years of medical education to which intelligent students are subjected, that doctors on the threshold of independent practice are either insufficiently inquisitive or lacking in self-confidence that they avoid the opportunity to undertake a simple study. 
Opinions of quality assurance will determine whether family doctors participate willingly or reluctantly in this aspect of medical care. Whilst the attitudes revealed by this study are generally favourable, there is agreement that external review is the least valuable form of quality assurance. This may reflect the wish of doctors to remain self-regulating rather than being monitored by management, however benign the managers claim to be. In the UK the course organizers preferred personal studies, whilst in the USA peer review and outcome review were seen as the more acceptable alternative to external review. However, in both countries there is a movement towards extended management and the external monitoring of care, and if the professions wish to resist this progression, they will have to show convincingly that personal studies, peer review and outcome review by doctors themselves are better methods for assuring the quality of care.

The methods used for teaching quality assurance do seem to be sufficiently varied, and to be employed in most schemes. The structure of training programmes in the two countries may influence these methods. In the UK, the apprenticeship style with attachment to a single trainer may favour more practice-based study and facilitate projects. In the USA, trainees are more likely to be part of a team of 'residents' attached to a single university practice, and this may more easily allow morbidity conferences. However, the quality of teaching for family practice graduates cannot be ascertained from this study. Simply because an activity is reported to be undertaken does not mean that educational objectives have been met, so this study cannot completely reveal which country provides the more advanced teaching of quality assurance to trainees. Before it is accepted that training in the UK is as rigorous as in the USA, other evidence should be considered. Quality assurance has long been part of medical practice in the USA, whereas it is relatively new in the UK. Quality assurance in the training of at least some family doctors in the USA was introduced several years ago (Sadler et al. 1977). It has been suggested that the teaching of the allied subject, cost containment, is more developed in British medical schools (Turner et al. 1985), although a comprehensive programme has been reported from one centre in the USA (Garg \& Kleinberg 1984), and others have shown the widespread introduction of formal programmes on this subject in US medical schools nearly a decade ago (Hudson \& Braslow 1979). Quality assurance is a complex topic, and it may be that in the UK appreciation of the details of quality assurance has yet to develop, with training at present being undertaken on a relatively simple level. In view of the current debates about medicine in general, and family practice in particular, the teachers of family doctors in both the USA and UK would be wise to review the place of quality assurance in the curricula of training courses, and the methods appropriate to teaching this subject.

\section{References}

Day P. \& Klein R. (1986) Controlling the gatekeepers: the accountability of general practitioners. Journal of the Royal College of General Practitioners 36, 129-30.

Garg M.L. \& Kleinberg W.M. (1984) Clinical Training and Health Care Costs: $A$ Basic Curriculum for Medical Education. Praeger Publishers, New York.

Hudson J.I. \& Braslow J.B. (1979) Cost containment education in United States medical schools. Journal of Medical Education 54, 835-40.

Irvine D. (1983) The quality of care in general practice: our outstanding problem. Journal of the Royal College of General Practitioners 33, 486-90.

Rosenblatt R.A. \& Moscovice I.S. (1984) The physician as gatekeeper: determinants of physicians' hospitalization rates. Medical Care 22, 150-9.

Sadler G.R., Snope F.C. \& Currie B.F. (1977) A quality assurance program for graduate education in family medicine. Journal of Family Practice 4, 751-2.

Tumer B.J., Grisso J. \& Heller R.F. (1985) Cost containment education in British medical schools: implications for American medical schools. Journal of Medical Education 60, 483-5.

Secretaries of State for Health, Wales, Northern Ireland and Scotland (1989) Working for Patients. Her Majesty's Stationery Office, London.

Secretaries of State for Social Services, Wales, Ireland and Scotland (1986) Primary Health Care: An Agenda for Discussion. Her Majesty's Stationery Office, London.

Yankauer A. (1980) Editorial: Who shall deliver primary care? American Journal of Public Health 70, 1048-50.

Received 20 April 1989; editorial comments to authors 23 June 1989; accepted for publication 14 September 1989 